\title{
Social Protection for Poverty Reduction: A Reply to Kabeer
}

\author{
Timo Voipio
}

It is easy for me to agree with most of Naila Kabeer's comments. In fact, it may be worth emphasising that albeit a constructive consensus was achieved among POVNET members on pro-poor growth and social protection, this does not mean that all our colleagues in the donor headquarters and country offices would understand - or agree with - what we have said and agreed in the POVNET. None of the donor agencies are internally completely coherent, and each agency has a more 'economistic' and a more 'social' face, depending on who represents the agency.

Kabeer rightly refers to the OECD as a 'rich country club'. However, in this case, she is wrong in assuming that the intention of the POVNET members is to negotiate the ultimate 'truths', 'wisdoms' and 'recipes' about social protection first among the donor members, and only then to disseminate them to developing country partners as glossy and authoritative OECD Guidelines.

In the work-plans of the POVNET Task Team on Social Protection, we have strongly emphasised the need to engage in dialogues and consultations with professionals of social protection in the 'Global South', including the national experts of developing countries as well as our colleagues in the donor embassies and country offices, who work closer to the people whose life realities we seek to influence.

Professional networking nowadays takes place increasingly through e-mail, internet and video- and tele-conferencing. In these processes, the real physical distances lose their relevance, as long as we at least every now and then get an opportunity to meet face-to-face, too.

Kabeer assumes that donor agencies may be afraid of the high costs of social protection schemes. This is, indeed, a common fear, albeit misplaced in most cases, especially in those situations where regular, predictable social protection (e.g. in the form of universal social pensions or child grants) delivered by permanent national and local government structures can replace enormously expensive 'emergency' or 'humanitarian' assistance' or food aid operations managed by donor agencies or developing country governments, often too late and too little, but always with huge transaction costs, which can be substantially lowered, e.g. by transferring cash instead of food aid imported from overseas.

Kabeer's analysis of the differences between the World Bank's thinking on social risk management and the Nordic idea of comprehensive social policy is sharp and accurate. Ultimately, the difference is ideological: in the Nordic thinking, social protection is not only an essential pillar of a sustainable (propoor) growth strategy - as for the World Bank, and for the POVNET Guidelines on Pro-Poor Growth but it is also a human right, as per Article 25 of the Universal Declaration of Human Rights. In this sense, the Nordic thinking is much closer to the ILO than to the World Bank.

Kabeer rightly suggests that the deepening of insurance markets through public-private micro-insurance and reinsurance arrangements may be centrally important in enabling poor people to engage in higher profit/productivity livelihood activities and reducing their reliance on debilitating crisis coping strategies

I would emphasise that both public and private as well as both micro- and macro-institutions may be needed in social protection. As regards insurance, public schemes often have the natural advantage that the populations among whom risks are pooled are larger, and therefore statistically more feasible. 
Most of the work of the POVNET Task Team on Social Protection focused on the management of social risks. However, the need for enterprise/business risk management among the micro- and small enterprises of poor people is large, too. For example, rainfall insurance has turned out to be a manageable form of insurance against harvest losses.

Health-related risks are 'hybrids' in the sense that for many poor families ill health is not only a social risk but also an enterprise/business risk; physical labour is often the most important factor of production that poor people depend on. ill health, therefore, is for many poor families, the most serious impoverishing factor. For this reason, health insurance should be considered not only a 'social' risk management instrument but a 'pro-growth' 'business risk' management instrument too.

The final conclusion and recommendation by Kabeer is very welcome. The discussions in the Task Team have, indeed, increasingly turned towards the need to identify who might be the various 'permanent champions' of social protection, inclusion, equity and empowerment in developing countries.

\section{Reference}

Kangas, O. and Palme, J. (2005) Social Policy and Economic Development in the Nordic Countries, Basingstoke: United Nations Research Institute for Social Development (UNRISD) and Palgrave Macmillan
A change agenda driven by donor projects and representatives alone cannot be sustainable, unless the national ministries and authorities responsible for social protection, employment and empowerment plus their social partners, related research institutes and media - and broader social movements have the will and skill to articulate the needs for, and human rights to social protection in, national policy dialogues and budget struggles, and to bargain for the effective and equitable implementation of these rights as a national priority.

Such power struggles are not easy - but they are necessary: Historical evidence from 'late industrialisers' shows (Kangas and Palme 2005) that the future prospects are much brighter for those nations that start to develop their social protection systems early - before they have become rich than for those who delay and neglect the design, piloting and mainstreaming of the instruments of social protection, inclusion, and empowerment, hoping to become first rich and invest in social policy only thereafter. 